\title{
Trabalho escravo contemporâneo: tempo presente e usos do passado
}

\author{
María Patricia Pensado Leglise
}

\section{GOMES, Angela de Castro; GUIMARAES NETO, Regina Beatriz. Trabalho escravo contemporâneo: tempo presente e usos do passado. Rio de Janeiro: FGV Editora, 2018. 200 p.}

El trabajo, al igual que muchos, si no es que la mayoría, de los temas que tienen que ver con la actividad humana, no es un "hecho de la naturaleza" sino que se trata de un fenómeno que se ha visto modificado, tanto en su forma como en su contenido, a lo largo de las civilizaciones. En La condición humana (España, Paidós, 1993) dice la filósofa Hannah Arendt: "La Edad Moderna trajo consigo la glorificación teórica del trabajo, cuya consecuencia ha sido la transformación de toda la sociedad en una sociedad de trabajo" y, desde este mirador es que el libro Trabalho eslavo contemporaneo: tempo presente e usos do passados de Angela Castro Gomes y Regina Guimaraes Neto, nos ayuda a mirar mejor cómo una de las características del trabajo en la era moderna sigue siendo la superexplotación, concepto acuñado por Ruy Mauro Marini que refiere a una forma particular de

Pesquisadora do Instituto de Pesquisa Dr. José María Luis Mora (CONACYT). Doutora em Estudos LatinoAmericanos pela Universidade Nacional Autônoma do México (UNAM). Professora de História LatinoAmericana no Sistema Universidade Aberta e a Distância da Faculdade de Filosofia e Letras da UNAM. Especializou-se em estudos contemporâneos da América Latina e Caribe e realizou pesquisas de História Oral sobre movimentos sociais no México, histórias de vida de militantes à esquerda em comunidades urbanas em Cidade do México. E-mail: ppensadol@yahoo.com.

1 La palabra esclavo dejó de usarse en el código penal brasileño en 1888. 
operaración del sistema productivo.

El texto es un recorrido útil, bien documentado, de la historia de las actividades agrarias en la región norte de Brasil, entre cuyas características resalta precisamente el esclavismo, fenómeno que por cierto, al amparo de las formas de producción globalizadas, ha vuelto a ocupar "puestos" importantes bajo las firmas - y formas - de capital maquilador.

Es notable el trabajo de estas historiadoras, quienes cuidan todos los aspectos, para señalar y denunciar de manera enfática la permisibilidad que han tenido diversas autoridades en Brasil para "tolerar" el trabajo esclavo, trabalho análogo ao de escravo (trabajo análogo al del esclavo) y cómo esta situación, que vulnera derechos humanos fundamentales, ha servido como bandera de lucha, consigna común, asumida por diferentes grupos sociales (médicos, abogados, sacerdotes y cientistas sociales) quienes a través de pequeños avances y dolorosos retrocesos, han logrado la promulgación de algunas leyes que protegen a los trabajadores rurales.

Protección legal necesaria porque, como las autoras enfatizan una y otra vez, el trabajo esclavo más allá de los derechos laborales implica un rechazo a reconocer, en esos hombres y mujeres su derecho a la ciudadanía. Personas rebajadas a algún estatus pre-humano, que estuvieran "destinadas" a formas de superexplotación, con nula o elemental calificación y a vivir en condiciones precarias. Desplazadas por las condiciones y arrojadas a aceptar cualquier tipo de trabajo.

Es de atender, sin duda alguna, el llamado de las autoras por evitar que discursos xenófobos, además de populistas, puedan permear y permitan aclimatar en y entre la comunidad que, bajo la mirada interesada de tejer discursos excluyentes, estos trabajadores sean vistos como "representantes de lo otro", "lo diferente" y en esa medida su condición resulte "natural y merecida".

El libro comienza con la experiencia de los médicos sanitaristas (la medicina pública), a inicios del siglo XX, cuya tarea era diagnosticar y curar las enfermedades en y entre las poblaciones rurales, sobre todo de personas de ascendencia africana quienes "descubrieron" que las enfermedades tenían relación con el trabajo que se desempeńaba y no, como era común en varios sectores "ilustrados", no resultado de fenotipo alguno.

Nos recuerdan que durante el llamado "Estado Novo" dirigido por el presidente Getulio Vargas (1937-1945), se integró al código penal la prohibición del trabajo análogo al de esclavo pero que, tras el golpe militar en 1964 y los regímenes cívico militar que siguieron, se volvió a echar mano de esas prácticas para hacer avanzar sus proyectos de colonización de la Amazonia, acompañada de la explotación de las actividades ganaderas y mineras.

Si bien, señalan las autoras, al trabajo esclavo queda definido "(cuando el 
sujeto se expone) a condiciones tan indignas y violentas que su propia vida puede encontrarse en riesgo", (p. 13) estamos ante un fenómeno que no sólo existe en el campo sino también en las urbes.

También conviene mencionar que entre otros atributos del libro está la reunión de fuentes y disciplinas de las ciencias sociales y de las humanidades, así como la utilización de entrevistas orales. Importante resulta la vasta bibliografía y hemerografía; incluye referencias de derecho laboral, historia, antropología, sociología y geografía brasileña. Pero también una lista de medios informativos impresos. En cuanto a la realización de entrevistas el abanico de sus fuentes consultadas es amplio; se realizaron entrevistas con los trabajadores del campo pero, también, con procuradores, auditores, magistrados.

Es de llamar la atención los testimonios de quienes frente al proyecto gubernamental de colonizar la Amazonia realizaron largos y difíciles peregrinajes del sur y sureste al nordeste de Brasil que, en opinión de las autoras, no se trató de algo muy diferente de lo que ahora pasa con los cientos de desplazamientos que se dan entre regiones para trabajar en minería, construcción de hidroeléctricas, actividades agrícolas y agroindustriales pero, sobre todo, en el proceso de apropiación empresarial de la tierra.

Situación que se ha agravado a raíz de los cambios a la Ley del Trabajo en 2017, que agregó las categorias de temporal e intermitente que dejan "disponible" al trabajador para mejor uso de la empresa o persona que lo requiera.

Guimaraes Neto y de Castro dedican un capítulo a seguir el debate que desde el siglo XX ha buscado reconocer, definir y prohibir el trabajo análogo al del esclavo; tema complejo, como lo indican, al que no es fácil dar por terminado. Va más allá, apuntan, de una cuestión semántica, ya que se trata de una realidad social donde es posible el "desarrollo de políticas públicas (adecuadas) no solo por la vía de la criminalización de los culpables, sino principalmente de ofrecer garantías a los explotados" (p. 33).

Por ello es que entre los problemas que emergen está el de la enorme dificultad de poder referirse hoy al trabajo esclavo en tanto no hay correspondencia exacta con el concepto de la esclavitud tenido en los siglos que van del XVI al XIX. Ante ello, nuestras autoras definen el fenómeno de la esclavitud "como un conjunto de prácticas de utilización de mano de obra no libre pues está sujeta a coerción y control violento, no más de un propietario (slaveowner), pero de un patrón/ dueño (slaveholder)” (p. 35).

Recuerdan que desde 1993 la Organización Internacional del Trabajo (OIT) denunció la existencia de millones de personas en todo el mundo, Brasil incluído, y que en 2014 "los cálculos de la OIT eran de que 21 millones de personas [...] producía una ganancia de 150 billones de dólares por año” (p. 87). 
Notorio es el énfasis que hay en el libro por resignificar el pasado desde el presente, para sostener "Una estrategia política que moviliza las relaciones entre historia y memoria para afirmar derechos, en este caso los derechos humanos, vinculados a los del trabajo" (p. 77). Por ello se proponen "La construcción de "pasados" y del vínculo entre "pasados" establece, así un diálogo intenso entre memoria e historia, una vez que se sabe que la memoria de un grupo es un factor fundamental para su cohesión interna y su identidad" (p. 82).

Particular interés pusieron las autores en lo que llaman "un itinerario historiográfico que privilegió experiencias en el tiempo y en el espacio por medio de los relatos de vida" (p. 129), cuyo resultado fue la realización de varias entrevistas, personas que participaron de distintas formas, cabe destacar la de algunos miembros de la organización católica llamada Comisión Pastoral de la Tierra (CPT), que empeñó esfuerzos por informar sobre la localización de haciendas que mantenían a sus trabajadores en condiciones de esclavitud. Mención especial les merece el obispo D. Pedro Casaldáglia, dirigente del Comité, cuyo documento "Una iglesia en conflicto con el latifundio y la marginación social” - escrito en 1971 - resultó muy importante.

También el relato de la doctora Ruth Villela, del Ministerio Público del Trabajo, da cuenta de la larga discusión para reconocer y legislar el trabajo análogo al del esclavo, en el cual fue de gran ayuda las consideraciones de la Organización Internacional del Trabajo (OIT), lo que llevó a la modificación del artículo 149 del Código Penal (2003) al establecer la concepción de dignidad humana, como dimensión inalienable y no negociable y, también a la afirmación del trabajo decente en la Constitución brasileña de 1988 y a la propia Declaración Universal de los Derechos Humanos.

Pero, las reflexiones de Guimaraes Neto y de Castro no dejan de lado el aspecto de la conciencia social. Así, refieren que es el caso que los propios trabajadores no se reconocen como esclavos, sino como peones, trabajadores que realizan actividades más pesadas porque no cuentan con la preparación adecuada para el desempeño de otras actividades y, al mismo tiempo, tampoco creían ser merecedores de derechos ciudadanos, llaman la atención en la importancia de la educación para ir construyendo la conciencia de ser depositarios de derechos y, en esa medida, deberes.

Cabe acotar, antes de dar paso a otros testimonios, que el proyecto de colonización de la región amazónica fue producto de la inversión económica de empresarios del sur y sureste de Brasil, quienes recibieron incentivos fiscales, en especial la liberación de recursos de la Superintendencia del Desarrollo de la Amazonia (SUDAM). Así se demostraba, en opinión de las autoras, el modus operandi del capital con apoyo de los gobiernos militares (1964-1985), en medio de conflictos sociales (p. 132). El resultado, como ya se mencionó, fue que los trabajadores desplazados de otras 
regiones (como el caso de Matto Grosso), constituyó un padrón de ocupación y exploración de la tierra y del uso y abuso de los trabajadores que no sólo subvaloraban su trabajo sino que era sujeto de violencia física y malos tratos por parte de sus empleadores (empresas y haciendas).

Al respecto el relato de Aparecida Barboza da Silva, presidenta del Sindicato de Trabajadores Rurales de Confresa es muy significativo, de ahí que las autoras profundicen en su trayectoria de vida. Su testimonio trasciende el relato personal ya que alude a muchas personas y circunstancias vividas: "El yo deja de ser la causa y el punto inicial de una secuencia de acontecimientos para agregarse a un conjunto de acciones asociadas al colectivo" (p. 172). Y es este punto, el que les permite a las autoras conocer experiencias en la lucha sindical, como la articulación con otras fuerzas políticas así como de otros agentes sociales ubicados en el campo jurídico, el apoyo de sacerdotes y obispos, así como de sindicatos rurales y abogados del CPT. Con lo cual se demuestra la importancia del trabajo pastoral y la presencia de la teología de la liberación en los conflictos del campo brasileño.

Barboza da Silva recibió denuncias de su empresa y de otras, donde era común la violación de los derechos de los trabajadores, entre otros extensión de la jornada, retención de documentos, falta de asistencia médica, alimentación precaria o falta de agua potable.

Para las autoras, la participación de Barboza da Silva fue fundamental para que el Ministerio del Trabajo y Empleo (MTE) conociera las denuncias lo que contribuyó a visibilizar el trabajo esclavo. Además, Barboza da Silva estableció y mantuvo relaciones con varios sindicatos de trabajadores rurales e instituciones estatales como los ministerios de Justicia, Público del Trabajo, del Trabajo y Empleo, la Secretaría de Derechos Humanos, y la Prelazia de San Felix do Araguaia y la Comisión Pastoral de la Tierra (CPT).

El libro a la vez que revela una realidad que, podría pensarse, se había superado, da cuenta de la lucha de los trabajadores y del reclamo de derechos humanos elementales como lo es el de ciudadanía. En mi opinión, un acierto de Guimaraes Neto y de Castro es su argumentación sólida por reconocer la categoría de trabajo esclavo contemporáneo para poder definir, con toda claridad, una categoría específica de explotación. Forma que, contra lógica de progreso, entendido como un mejoramiento continuo de condiciones humanas y sociales, pervive no sólo en los países del capitalismo tardío, sino también en los llamados desarrollados y que se jactan de tener gobiernos democráticos.

Recebido em 09/10/2020

Aprovado em 10/11/2020 